\title{
Inter-annual dynamics and persistence of small mammal communities in a selectively logged tropical forest in Borneo
}

\author{
Philip M. Chapman ${ }^{1,2}$ (D) Oliver R. Wearn² $\cdot$ Terhi Riutta $^{1,3} \cdot$ Chris Carbone $^{2}$. \\ J. Marcus Rowcliffe ${ }^{2} \cdot$ Henry Bernard $^{4} \cdot$ Robert. M. Ewers $^{1}$
}

Received: 28 November 2017 / Revised: 18 July 2018 / Accepted: 21 July 2018 / Published online: 2 August 2018 (c) The Author(s) 2018

\begin{abstract}
Understanding temporal change and long-term persistence of species and communities is vital if we are to accurately assess the relative values of human-modified habitats for biodiversity. Despite a large literature and emerging consensus demonstrating a high conservation value of selectively logged tropical rainforests, few studies have taken a long-term perspective. We resampled small mammals $(\leq 1 \mathrm{~kg})$ in a heavily logged landscape in Sabah, Borneo between 2011 and 2016 to investigate temporal patterns of species-level changes in population density. We found that small mammal population density in heavily logged forest was highly variable among years, consistent with patterns previously observed in unlogged forest, and uncovered evidence suggesting that one species is potentially declining towards local extinction. Across nine species, population densities varied almost sevenfold during our 6-year study period, highlighting the extremely dynamic nature of small mammal communities in this ecosystem. Strictly terrestrial murid species tended to exhibit strong temporal dynamics, whereas semi-arboreal foraging species such as treeshrews had more stable dynamics. We found no relationships between population density and fruit/ seed mass, and therefore no evidence that our patterns represent responses to inter-annual mast fruiting of the dominant canopy dipterocarp trees. This may be due to the removal of most of the canopy during logging, and hence the dipterocarp seed resource, although it possibly also reflects spatiotemporal limitations of our data. Our results underline the importance of understanding long-term variability in animal communities before developing conservation and management recommendations for human-altered ecosystems.
\end{abstract}

Keywords Tropical forest $\cdot$ Population dynamics $\cdot$ Logging $\cdot$ Temporal change $\cdot$ Small mammals

Communicated by David Hawksworth.

This article belongs to the Topical Collection: Forest and plantation biodiversity.

Electronic supplementary material The online version of this article (https://doi.org/10.1007/s1053 1-018-1594-y) contains supplementary material, which is available to authorized users.

Philip M. Chapman

p.chapman14@imperial.ac.uk

Extended author information available on the last page of the article 


\section{Introduction}

Across tropical forest ecology, there is now a broad consensus that selectively-logged and regenerating forests retain relatively high species richness (Berry et al. 2010; Edwards et al. 2014a, b; Bernard et al. 2016; Costantini et al. 2016; Wearn et al. 2016). This is particularly true when compared to intensive agriculture such as oil palm plantations, which are rapidly replacing these forests (Fitzherbert et al. 2008; Sodhi et al. 2010; Gibson et al. 2011; Warren-Thomas et al. 2015; Wearn et al. 2016). Limited conservation resources mean practitioners must prioritise areas containing high species richness and biologically irreplaceable taxa, but we must also preserve communities which are resilient through time in the face of environmental change. However, temporal resilience of animal communities in selectively logged tropical forests remains understudied. Across 78 studies described in two recent meta-analyses (Putz et al. 2012; Costantini et al. 2016), 22 sampled plots of more than one logging age, and only 13 made direct statistical comparisons of abundance, species richness or community composition among logging ages. Only seven studies resampled locations, with only two resampling more than 2 years apart (Bischoff et al. 2005; Akutsu et al. 2007). The remaining 71 studies based their conclusions on a single sample of each location.

This represents a potentially serious knowledge gap, as richness, abundance and community composition are unlikely to remain constant over time for two reasons. Firstly, tropical climate and rainfall vary inter-annually via global-scale processes such as the El Niño Southern Oscillation (ENSO). Particularly in South-East Asia, ENSO drives interannual biotic processes such as mast fruiting of trees, causing fluctuations in abundance of granivorous insects (Nakagawa et al. 2003) and small mammals (Curran and Leighton 2000; Emmons 2000; Nakagawa et al. 2007b, c; Wells et al. 2007). There is some evidence that this process remains important after logging, albeit with altered intensity (Appanah and Rasol 1990; Curran and Webb 2000). Secondly plant community succession occurs through time, from short-term responses such as increased leaf and fruit production (Johns 1988), to gradual community compositional changes and reversion of biotic and abiotic conditions towards a primary forest-like state (Curran et al. 1999; Brearley et al. 2004; Liebsch et al. 2008). Fluctuating background resource availability, succession, or successive logging rotations are all likely to modify species interactions and niche availability. Species may respond by invading and increasing abundance, fluctuating, or declining to local extinction rapidly, or gradually (i.e. extinction debt; Ferraz et al. 2003; Kuussaari et al. 2009; Wearn et al. 2012). Net temporal changes to community structure may therefore be complex.

Short-term "snapshot" biodiversity assessments, such as the majority we examined above, generally cover at most one or two generations of the focal taxa. In failing to capture temporal dynamics, such studies risk generating erroneous management recommendations, under-allocating resources to species in extinction debt, and skewing long-term estimates of ecosystem processes such as seed dispersal or herbivory. To avoid these outcomes, and capture the long-term biodiversity value of logged forest, population- and community-level studies should ideally measure changes in both diversity and abundance through time, ideally starting before logging but at least covering multiple generations of the focal taxon, with regular, standardised monitoring techniques (Lindenmayer et al. 2012). Such studies are understandably rare, as the necessary sampling effort is logistically and financially challenging, however they provide insights which would otherwise be missed (Lindenmayer et al. 2012). 
Among the most functionally important animal groups in tropical forests are small mammals, which are major seed predators (Asquith et al. 1997; Curran and Webb 2000; Wells and Bagchi 2005). Despite a sizeable literature examining communities in fragmented systems (Pardini 2004; Püttker et al. 2008; Vieira et al. 2009; Gibson et al. 2013), small mammals remain understudied in continuous logged forest, particularly in SouthEast Asia (Meijaard and Sheil 2008). We found only two studies examining temporal patterns of abundance or species richness in continuous logged forest (Isabirye-Basuta and Kasenene 1987; Wells et al. 2007). Both studies chiefly considered intra-annual reproductive trends, and did not explicitly examine patterns over longer timeframes. Isabirye-Basuta and Kasenene (1987) demonstrated intra-annual species abundance fluctuations over a four-year period in Uganda, with increasing amplitude and reduced population stability in logged versus unlogged forest. Conversely, Wells et al. (2007) found little difference in abundance fluctuations, community evenness and dominance between Bornean logged and unlogged forest. Although both studies provide some evidence that complex temporal patterns seen in unlogged forest are retained with varying magnitude after logging, they are methodologically limited by small sample size, and short duration respectively, and neither study accounted for detection probability, a common limitation of ecological studies (Kellner and Swihart 2014). To our knowledge no study has explicitly examined population dynamics of small mammals between years in logged forest; or considered either extinction debt, or interannual fluctuations.

Here we examined population dynamics of a small mammal community over a 6-year period in a continuous, heavily logged forest landscape typical of the large areas in South East Asia threatened by conversion to plantation agriculture. Uniquely, we resampled our communities annually, in identical locations controlling for aspect, topography and altitude. We controlled for imperfect detection using mark-recapture modelling, and tested for inter-annual variation in density, including long-term declines. We also tested for a likely causal factor by examining the relationship between small mammal population density and the density of seed and fruit rain. We reveal temporal patterns of community variability and persistence, and discuss the implications for landscape conservation of mammal communities.

\section{Methods}

\section{Study area}

We collected field data at the Stability of Altered Forest Ecosystems (SAFE) project in Sabah, Malaysian Borneo (Ewers et al. 2011), a landscape-scale experiment situated within a 1-million ha multi-use forest concession owned by Yayasan Sabah (Sabah Foundation). The SAFE site, and the Yayasan Sabah concession in general, consists of selectively-logged lowland dipterocarp forest. Most of the area has been subject to at least two rounds of selective logging between the 1980s and the 2000s, a landscape history typical of Sabah and the wider SouthEast Asian region (Johns 1997; Putz et al. 2012). Most large, commercially valuable timber trees were felled and removed, with an estimated cumulative $302.8 \mathrm{t} \mathrm{ha}^{-1}$ of aboveground tree biomass removed (Pfeifer et al. 2016), leaving continuous, spatially heterogeneous forest which is among the most heavily logged forest in the tropics (Burivalova et al. 2014). Our sites were not logged during the period of this study from 2011 to 2016, however some piecemeal salvage logging occurred within the wider landscape during this timeframe. Detailed 
locations, timings and extraction densities were not available, however no logging occurred within $100 \mathrm{~m}$ of our sites.

\section{Live-trapping grids}

Using a standardised sampling grid (Wearn et al. 2017), we sampled small mammals annually from May 2011 to July 2016, with a gap in 2013 during which no sampling was conducted for logistical reasons. We maintained a permanent trapping effort of eight grids, which were each resampled once per year; plus eight additional grids which were trapped once, four each in 2011 and 2012 (for a map of our sampling sites, see Wearn et al. (2017). We trapped all grids between December and July, although matching exact dates and trapping order between years was not practical.

Each grid comprised a $4 \times 12$ array of sampling points with $23 \mathrm{~m}$ separation. We placed two "Tomahawk"-style steel cage traps within a 5 m radius of each point, for a total of 96 traps covering approximately 2.1 ha, (Cusack et al. 2015; Wearn et al. 2016, 2017). We sited the two traps at each sampling point on approximately $180^{\circ}$ opposed bearings, but preferentially chose microhabitat features providing cover for small mammals (e.g. dense ground vegetation, fallen wood, roots, or rocks). We placed all traps at ground level, or $\leq 0.5 \mathrm{~m}$ on fallen logs. We took care to sample at precisely the same locations during each year of the study, although there was occasional positional error, either where we resited traps due to tree falls, landslips or ant nests; or where positions were shifted accidentally due to steep topography or by large mammals. We considered these errors negligible for the purposes of this study.

\section{Trapping and processing protocol}

One sampling session for each grid consisted of seven consecutive trap nights annually. Each trap was covered with a black polythene wrapping to provide waterproofing and shade for captured animals, baited with one ripe oil palm fruit and left for approximately 20-24 h before checking. We checked all traps daily in the early morning, and processed and individually marked all new small mammal captures before releasing them at the original capture location within $1 \mathrm{~h}$. Following the ethical trapping and handling guidelines issued by the American Society of Mammalogists (Sikes et al. 2011), we released highly stressed or sick animals immediately without processing, or humanely euthanised ( $<1 \%$ of captures) where animals were severely sick or injured. Prior to each season, our fieldwork was subject to a thorough ethical review process (via the Institute of Zoology, Zoological Society of London).

We identified individuals to species, and where possible aged and sexed all individuals using published information (Payne and Francis 1985), supporting this with biometric measurements (hind foot length, ear length, anogenital distance, weight, head-body length, tail length) where necessary. We marked new individuals with Passive Inductive Transponder (PIT) tags (Francis Scientific Instruments, Cambridge, UK), which allowed us to uniquely identify recaptured individuals at their capture location.

\section{Detectability controlled population density estimation}

The value of controlling for detectability in ecological surveys is a question under debate (Banks-Leite et al. 2014; Guillera-Arroita et al. 2014), with a large majority of studies not doing so (Kellner and Swihart 2014). Accounting for correlates of detection probability 
by good survey design may reduce the need for detectability-controlled measures of abundance, occupancy or species richness, which are frequently data-hungry and therefore restrict authors' abilities to study rare species (Banks-Leite et al. 2014). In the context of our study, however, accounting for imperfect detection is advisable. Most small mammals in tropical forests are dietary generalists, and many are plastic in their choice of foraging strata (Emmons 2000; Nakagawa et al. 2007a). Therefore the relative availability of seed and fruit on the forest floor compared to foods available in other strata—variability that may be particularly acute due to mast seeding - may affect foraging patterns and responses to bait (thus detection probability) independently of changes in density.

We calculated population density using spatially explicit capture-recapture modelling (hereafter SECR) using package secr (Borchers and Efford 2008; Efford 2013) in R version 3.0.3 (R Core Team 2018). First, we trimmed the capture data for each grid to only include animals which were tagged and positively identified. We then converted the trap location information (polar bearing and distance from the nearest of the 48 grid points) to an $\mathrm{X}-\mathrm{Y}$ coordinate system.

SECR models require a minimum quantity of recaptures to produce a reliable estimate of population density, with an approximate minimum of five recaptures generally recommended (Royle et al. 2013). Our SECR models grouped the density estimates by species, and to satisfy this assumption we therefore only included density estimates based on $\geq 5$ recaptures per species per year. Where rare species did not exceed this minimum for at least four (i.e. 50\%) of the grids in a given year, we excluded them from the analysis. Apart from these exceptions, SECR models were fitted to all the data for each grid, spanning all sampling sessions for 2011-2016.

We fitted maximum-likelihood SECR models using command secr.fit, modelling each grid separately and focusing on temporal changes in density between years. The model estimates three parameters from the data: the population density $(D)$, the "amplitude" of the detection function curve ( $\mathrm{g} O$, the detection probability at hypothetical home range centres), and the "width" parameter of the detection function ( $\sigma$, which is related to the animals' home range radius). These parameters may be constant or related to grouping factors, in our case the species and the sampling year. Accordingly, we specified models of increasing complexity (Table 1), and used a model selection approach to select the best model for each grid (lowest Aikake's Information Criterion [AIC]). We calculated estimates of population density for each species separately by using species identity as a grouping factor in the model. We then obtained annual community-level density estimates. We first summed the annual density estimates of all species within each grid to obtain a pooled estimate for grid-level community density, and then averaged these across grids to produce a landscapelevel estimate for each year. We then compared our density estimates among years using generalized linear mixed models with Gamma error family and the inverse link function (Package lme4, Bates et al. 2015). Since at least Tupaia treeshrews appear to show defined breeding seasons in this system (Emmons 2000), month of sampling is likely to confound our annual density estimates. We therefore included month as a random effect in all our models.

\section{Seed and fruit data}

To investigate the link between resource availability and small mammal population dynamics, we modelled our species-level density estimates against monthly average figures for seed and fruit rain. These data originate from two sources: (1) $1 \mathrm{~m}^{2}$ litter traps set once 
Table 1 Specifications of models used in the model selection process in this study. "Density" is the population density estimate, g0 is the maximal probability of detection of an individual at distance $=0$ from the hypothetical home range centre, and $\sigma$ is the width of the halfnormal detection function, all three of which may be held constant $(\sim 1)$ or made dependent on species or sampling year. The models were fitted separately for each sampling grid

\begin{tabular}{ll}
\hline Model specification & Comments \\
\hline Density species, g0 1, $\sigma \sim 1$ & Models for grids sampled in only one year \\
Density species, g0 1, $\sigma \sim$ species & \\
Density species, g0 species, $\sigma \sim$ species & Models for grids sampled in multiple years \\
Density species*year, g0 1, $\sigma \sim 1$ & \\
Density species*year, g0 1, $\sigma \sim$ species & \\
Density species*year, g0 species, $\sigma \sim$ species & \\
Density species*year, g0 species*year, $\sigma \sim$ species & \\
Density species*year, g0 species*year, $\sigma \sim$ species*year & \\
\hline
\end{tabular}

each at 96 sites across the SAFE project area during 2010-2011, and collected after two weeks; and (2) $0.25 \mathrm{~m}^{2}$ litter traps set at five permanent 1 ha carbon plots (25 per plot) during 2011-2016, collected every 2-6 weeks. The litter traps in (1) were located between 0 and $9.5 \mathrm{~km}$ from the grid locations, while the litter traps in (2) were between 0.4 and $10.2 \mathrm{~km}$ from the grid locations. Litter was oven-dried, sorted and weighed to give dry mass (g) of leaves, woody debris, flowers, fruit, and seeds. We pooled the fruit and seed data as the categorization is subjective and both are likely to be important to small mammals. We scaled the estimates to a uniform measure of $\mathrm{g} \mathrm{m}^{-2}$ month $^{-1}$, and averaged across the plots to give a landscape-scale monthly estimate of seed/fruit fall, which we believe is broadly representative of local-scale seed/fruit fall, both at background levels and during mast fruiting.

We modelled the species-level small mammal density estimates for each grid against the seed/fruit fall value for the relevant month in which the mammal trapping occurred, using generalized linear models with a log link function, and removing grids $(n=12$ or $26.7 \%$ of the total data) for which fruit and seed data for that month was not available. Since interannual peaks in fruit/seed availability should take time to reflect in an increased abundance of small mammals, we fitted models with seven increasing lag periods from 0 to 6 months, in each case fitting the small mammal data to the appropriate earlier month's seed and fruit data. We selected the best-fitting model in each case by comparing AIC values.

\section{Results}

\section{Trapping success, species richness and overall density}

In total we ran 45 grid sampling sessions of 7 days each across 2011, 2012, 2014, 2015 and 2016 (total $=30,240$ trap nights). We captured 2598 identifiable individual small mammals (mean trap success rate $=7.1 \%$ ), comprising 20 species. Mean observed species richness in 2011 was $12.6 \pm 0.6$; in 2012: $11.0 \pm 0.7$; in 2014: $8.8 \pm 0.4$; in 2015: 11.3 \pm 0.4 ; and in 2016: $10.6 \pm 0.5$. We captured nine species in sufficient numbers $(\geq 5$ recaptures in $\geq 4$ grids per year) to estimate density using SECR. These nine species cumulatively represented 2152 
individuals, or $83 \%$ of all individuals captured (Table 2). Whitehead's Rat Maxomys whiteheadi was the most commonly encountered species (23.2\% of individuals), with the Red Spiny Rat Maxomys surifer (18.6\%) also frequently encountered.

At the community-level, small mammal population density showed strong differences among years (generalised linear mixed model with inverse link, $\mathrm{F}=10.875, p<0.0001$, Fig. 1b). Density declined 34\% between 2011 and 2012 ( $p=0.004$, Fig. 1), and a further 30\% of 2011 levels between 2012 and 2014 ( $p<0.0001$, Fig. 1). By 2015 density had partly recovered, and did not differ significantly from 2012 levels, although it remained slightly lower in 2016 than in 2011 ( $p=0.05$, Fig. 1).

\section{Species-specific trends}

The best-performing density model for each grid is presented in Table S1 of Online Resource 1. The inter-annual changes in population density of individual small mammal species fell into two broad species subgroups, one of which had strongly fluctuating densities through time (Fig. 2a-c), and the second of which had more stable densities. The first, variable subgroup comprised six species that mostly had patterns that mirrored the overall trend in communitylevel density, as these species form the dominant component of the community $(77.9 \%$ of the individuals used for density estimation, Table 2). These species all declined strongly from 2011 to 2014, with marked synchrony between species and similar proportional losses of population density over this period. This subgroup comprised the terrestrial murids Maxomys whiteheadi (-74\%), M. surifer (-73\%), and S. muelleri (-81\%), along with the treeshrews $T$. longipes and $T$. tana, which declined less severely $(-61,-66 \%)$. These species recovered to varying degrees during 2015-2016 (Fig. 2a-c), with M. whiteheadi recovering most rapidly, S. muelleri and T. longipes also regaining their 2011 densities by 2016, but M. surifer and T. tana had not recovered by 2016 . The sixth species, M. baeodon, was already a comparatively rare species in 2011 and gradually declined throughout the course of study. Density was not significantly lower in 2014 than 2011, but by 2016 it had declined significantly to only $29 \%$ of the starting figure in 2011 (Fig. 2a).

The second subgroup comprised the treeshrew T. gracilis, and the semi-arboreal murids Leopoldamys sabanus and Niviventer cremoriventer. Although these species appeared to dip subtly in 2011-2014 (Fig. 2d), their dynamics were characterised by lower abundance, much higher between-grid variance around the annual estimates and no significant differences in population density among years.

\section{Relationship with seed density}

Density of fruit and seeds remained low throughout much of the time period from 2011 to 2016, however periodic spikes were evident in 2012, 2014 and 2015 (Fig. 3). Despite this, we found no significant relationship between seed density and population density for any of the species surveyed at any time lag (generalized linear models, all $p>0.05$ ).

\section{Discussion}

As the longest-duration study of a small mammal community in continuous logged tropical forest, our results underline the importance of understanding long-term trends in parameters such as population density for assessment of the value of logged forests for 


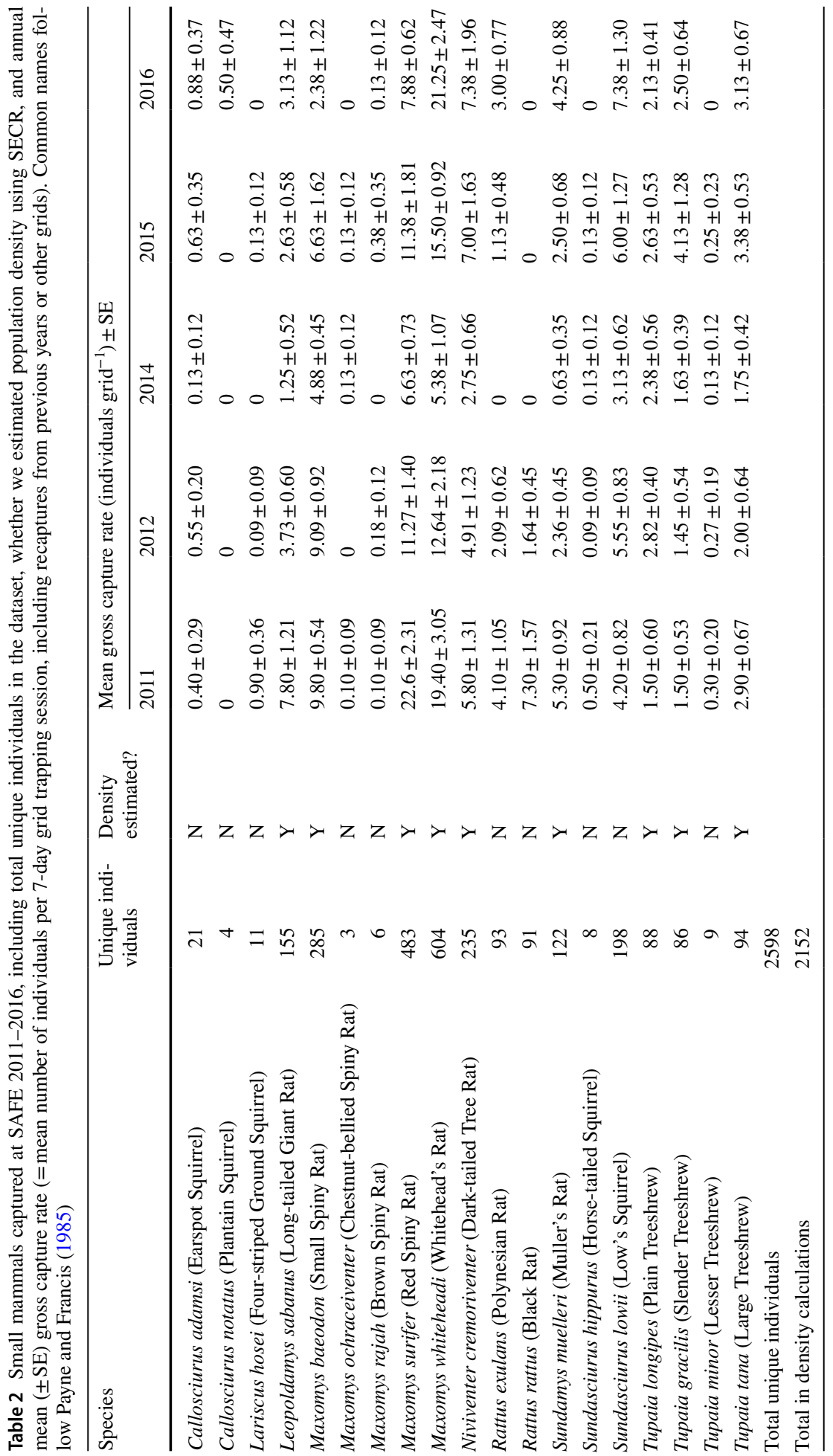


Fig. 1 Mean annual communitylevel population density of all small mammals from 2011 to 2016. Error bars: \pm 1 SE. Letters denote significance groups, with significantly different means not sharing letters

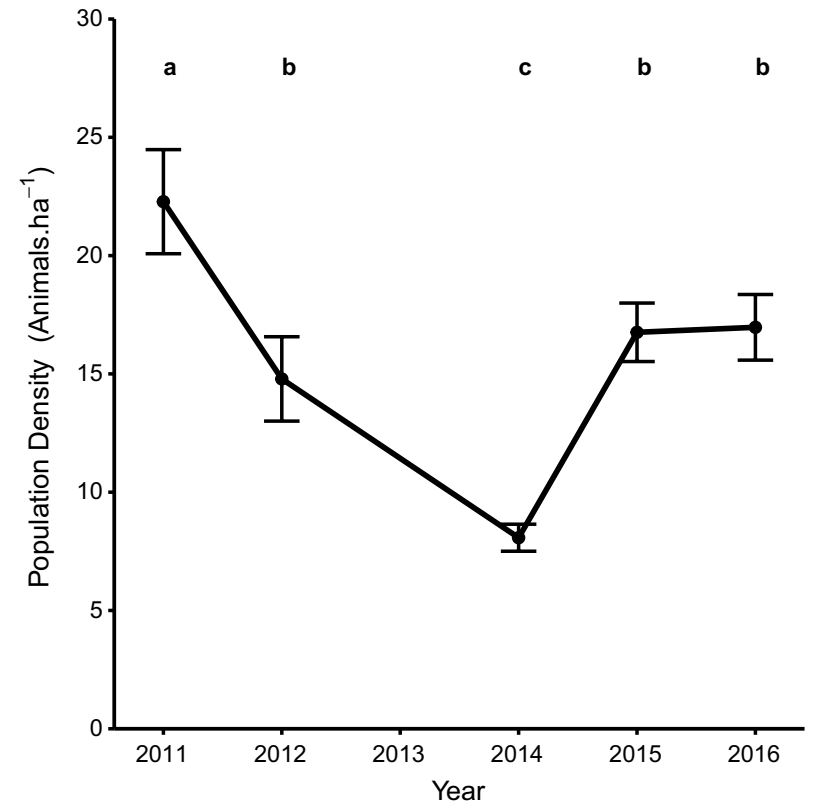

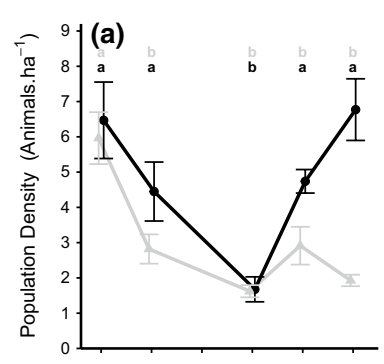

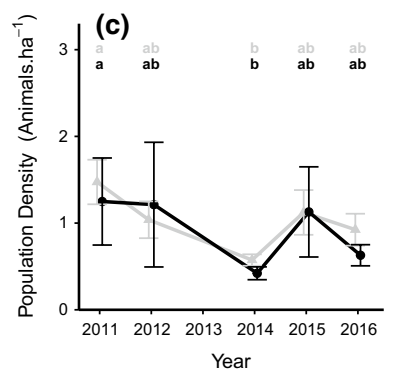

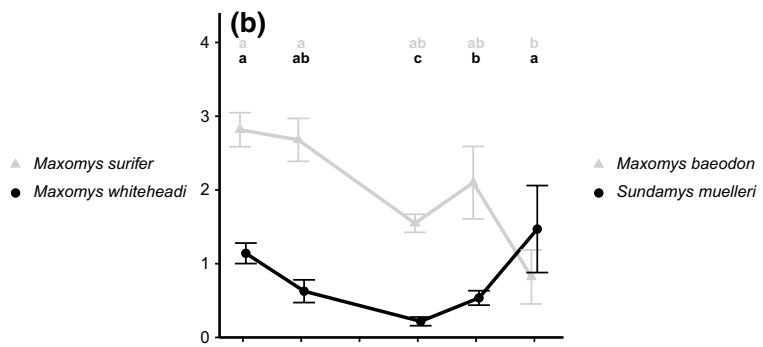

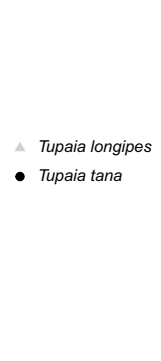

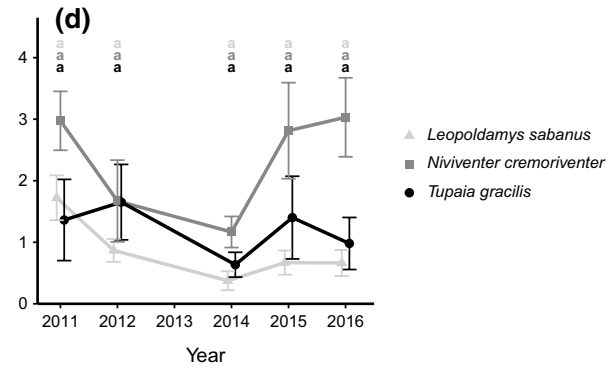

Fig. 2 Mean population density of nine small mammal species at the SAFE project 2011-2016. Error bars: \pm 1 S.E. a Maxomys surifer and M. whiteheadi. b Maxomys baeodon and Sundamys muelleri. c Tupaia longipes and T. tana. d Leopoldamys sabanus, Niviventer cremoriventer and Tupaia gracilis. Letters denote significance groups, with significantly different means not sharing letters

biodiversity. Previous studies have observed strongly variable dynamics in small mammal communities inhabiting undisturbed forests (Nakagawa et al. 2007b, c; Wells et al. 2007). Our results suggest that this variability persists inter-annually after intensive selective 
logging in two thirds of the species we examined, and in the community as a whole. We observed a high magnitude of inter-annual variation, with density reducing by up to $50 \%$ between consecutive years, and up to $80 \%$ in 2011-2014. This is similar to previous evidence; for example, community-level abundance in a Bornean unlogged forest declined by approximately 90\% from 1999 to 2002 (Nakagawa et al. 2007b).

The diet of Bornean small mammals is poorly known (Wells et al. 2007), although the small mammal species we examined are probably relatively functionally homogenous (terrestrial/low canopy generalists and granivores, see Payne and Francis (1985)). Nevertheless, our results demonstrate a range of inter-annual dynamics, particularly during 2011-2014. This variation in dynamics seems to follow an ecological gradient from strictly terrestrial murids (which exhibited strong temporal dynamics) to facultatively semi-arboreal foragers, including climbing murids and some treeshrews (which exhibited no strong temporal dynamics). The two treeshrew species which did vary between years (Tupaia longipes and T. tana) forage more terrestrially than T. gracilis (Emmons 2000), and showed intermediate variability. Strongly terrestrial small mammals are both more exposed to the vast excesses of dipterocarp seeds during mast events (Curran and Webb 2000); and are less plastic in their foraging strategies and less able to facultatively exploit food resources at other vegetation strata during inter-mast food shortages. These species may therefore be more responsive to masting than semi-arboreal foragers. Treeshrews generally have inadequate digestive systems to process dipterocarp seeds (Emmons 2000), but T. longipes and T. tana (both variable in our results) may react indirectly to masting if insect abundance at forest floor level is greatly increased during mast fruiting events (Nakagawa et al. 2003).

This relationship between population density dynamics and feeding ecology, plus the fact that largely synchronous patterns were broadly shared among functionally similar species suggest that the mast fruiting-driven fluctuating patterns seen in primary forests (Curran and Leighton, 2000; Nakagawa et al. 2007b), may persist after multiple rounds of logging. Indeed forests subjected to a single selective logging rotation may still produce sufficient fruit/seed volumes ( $23 \%$ of the primary forest figure) to attract a strong response from local seed predators (Curran and Webb 2000). However, we did not find any direct evidence supporting the expected seed density-mammal density relationship, which we suggest may be due to three factors.

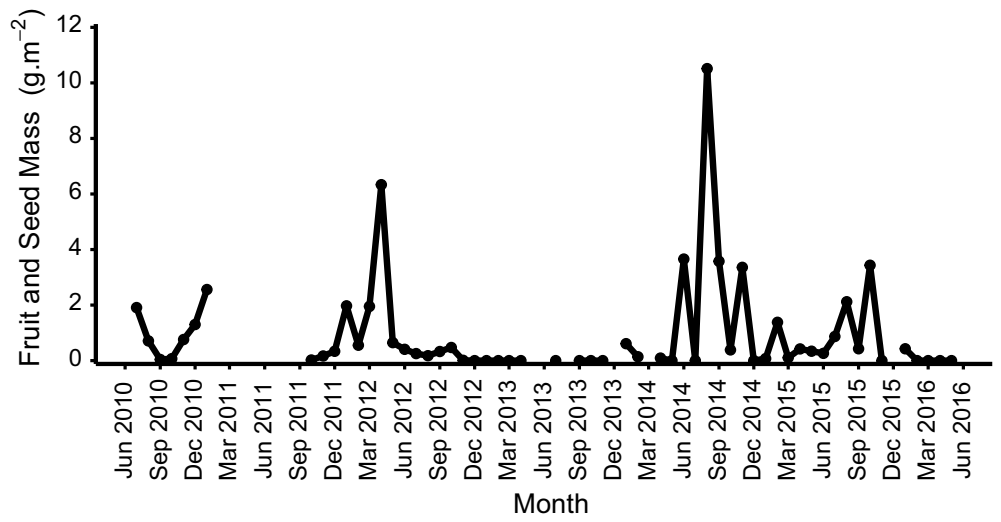

Fig. 3 Mean combined fruit and seed mass $\left(\mathrm{g} \mathrm{m}^{-2}\right)$ by month, captured in litter traps at the SAFE project, 2010-2016. Gaps represent missing data 
Firstly, the temporal extent of our data may still be insufficient to detect a relationship. According to Sabah-wide records, ENSO-driven droughts in Sabah occurred in 2010, and to a lesser extent in 2014 and 2015 (Ghazoul 2016). While we detected the 2014 mast event (Fig. 3), for most of the rest of 6-year survey period, the litter traps contained low quantities of fruit and seed despite the variable small mammal population density. Our first litter trap collection was carried out in the second half of 2010 (Fig. 3), so it is probable that we did not detect the major 2010 mast, which might have explained the high small mammal population densities at the start of our study in 2011. We also did not find evidence for the 2015 event, suggesting it might have been too minor and localized to occur in our study area.

Secondly, unlike the West Kalimantan site studied by Curran and Webb (2000), logging at SAFE has been subject to multiple rotations and the landscape retains few commercially valuable mature trees. Since logging in Borneo specifically and intensively targets the mast-fruiting Dipterocarpaceae (Johns 1997; Putz et al. 2012), it is possible that there are insufficient mast fruiting trees remaining in the landscape to drive significant changes in small mammal population densities, and that the variability that we observed may be regulated by other processes, such as bottom up control via other food plant taxa, or topdown control by predators.

Thirdly, even if logging damage at the landscape level is not sufficient to completely disrupt mast fruiting-driven changes to population dynamics, logging disturbance is highly spatially heterogeneous, and the forest at SAFE forms a patchwork of highly variable quality and tree cover (Pfeifer et al. 2015, 2016). Mast fruiting is already a spatially heterogenous process (Ghazoul 2016), and logging undoubtedly further localizes this by leaving small "islands" of mature dipterocarp trees. This is supported by the fact that fruit/seed rain levels were very weakly correlated between the five carbon plots which supply data for our study (average $\mathrm{R}^{2}=0.14$ ). These "islands" may be visited by our small mammals at some distance from the trapping locations, although the effect of habitat change on the ranging behaviour of our species is poorly-known. Our seed and fruit data were collected from plots at varying distance from our small mammal grids, and we could therefore use the data only to represent a landscape-level average fruit availability, rather than to detect very localized associations between fruiting and small mammal abundance.

\section{Conclusions and conservation implications}

Our results reveal dynamic inter-annual variability in small mammal population densities, but not necessarily a dynamic equilibrium. Even this 6-year dataset is insufficient to demonstrate inter-annual cycling of population density, with repeated peaks and troughs, which may require a decade or more of data. Furthermore, there is some evidence to suggest that the diversity of this community is progressively declining: the Small Spiny Rat Maxomys baeodon continued to decline gradually throughout the course of our study, and is potentially under extinction debt since the last major round of logging in the early 2000s. This, and the fact that the more abundant $M$. surifer failed to recover from the 2014 crash, contrast with the rapid recovery of $M$. whiteheadi, which is the most tolerant of the three to habitat degradation and the only Maxomys species able to persist in oil palm plantation (Wearn et al. 2017). Together, these three trends may represent an early hint that the terrestrial Maxomys sub-community is simplifying over time, perhaps by $M$. whiteheadi outcompeting less disturbance-tolerant congeners; 
however several years of further monitoring will be necessary in order to confirm this, as extinction debts in tropical forest small mammals may take 1-2 decades to become completely realized (Gibson et al. 2013).

Our results demonstrate the value of designing studies which take a long-term approach in order to assess the value of logged forests for biodiversity. This contrasts with the bulk of existing studies, which compare between primary forests, logged forests, and oil palm plantations based on single survey periods in each habitat, often not simultaneously across habitats or resampled within habitats. Previous work implies that this approach does not capture the temporal complexity of primary forest small mammals (Nakagawa et al. 2007b), and our results suggest this is also true of logged forests. Indeed, a survey of our communities in any randomly selected single year may have produced density estimates varying by up to $80 \%$. Such variation could affect conclusions and recommendations for conservation practice, which often requires prioritizing limited resources to protect the most biodiverse, resilient communities, and calculating minimum viable protected areas to support populations or communities. If the assumption that abundance remains approximately constant through time is not tested, and estimates of community abundances are drawn from different phases of the inter-annual dynamic (either due to spatial asynchrony in community dynamics, or temporal asynchrony in sampling), the data informing those decisions will not be easily comparable, and two surveys of similar communities might produce very different results, or vice versa. Errors such as these will also affect abundance-weighted functional diversity metrics (e.g. Villéger et al. 2008), and comparisons of ecosystem processes driven by small mammals, such as seed predation (Curran and Webb 2000; Guariguata et al. 2002).

We agree with Lindenmayer et al. (2012) that further emphasis is needed on longterm studies which regularly resample community or population parameters of interest in order to create temporally reliable estimates of the value of human-modified habitats for biodiversity. Clearly, not all taxa are likely to display equally temporally variable responses across all human-modified ecosystems. Our data suggest, however, that at least in some cases the taxa likely to be variable can be identified a priori from careful consideration of their ecological and functional characteristics. The need for a more temporally explicit understanding is most acute in systems such as South-East Asian tropical forests which are strongly influenced by inter-annual processes. Although such studies are logistically challenging, they will prove invaluable in understanding the biodiversity potential of human-modified ecosystems globally.

Acknowledgements We thank the Sabah Biodiversity Centre, Maliau Basin Management Committee and Sabah Forestry Department for fieldwork permissions. Anna Heath, Jess Haysom, Leah Findlay, Jeremy Cusack, Matthew Holmes, Faye Thompson, Robin Loveridge, and Jack Thorley provided field assistance; and field assistants and staff at the SAFE Project provided logistical support, particularly Ryan Grey, Ed Turner, Mohd. Sabri bin Bationg and Aleks bin Lukas. We thank David Orme for analytical advice and computing assistance, and Louise Hill for computing assistance. We thank the Sime Darby Foundation for funding this study via general support of the Stability of Altered Forest Ecosystems Project; and the UK Natural Environment Research Council for funding PMC via the Science and Solutions for a Changing Planet Doctoral Training Partnership at Imperial College London. This paper is a contribution to Imperial College London's Grand Challenges in Ecosystems and the Environment Initiative.

Funding This work was funded by the UK Natural Environment Research Council as part of a PhD studentship paid to PMC via the Science and Solutions for a Changing Planet Doctoral Training Partnership based at Imperial College London. It was also supported by the Sime Darby Foundation via general support of the SAFE project. Beyond financial support, neither of these organisations contributed to this study in conception, design, data collection, analysis, writing or decision to publish. 
Data availability The datasets generated during the current study are available in the Dryad Digital Repository, https://doi.org/10.5061/dryad.4th3p35.

\section{Compliance with ethical standards}

Conflict of interest The authors declare that no other conflict of interest affects this study.

Animal research As referred to in Sect. 2.3, live animals trapped for this study were handled according to the guidelines of the American Society of Mammalogists (Sikes et al. 2011). Before beginning fieldwork for this study, PMC and ORW obtained ethical review and clearance from the Animal Ethics Review Board of the Zoological Society of London, which was reviewed and renewed by the Board annually.

Open Access This article is distributed under the terms of the Creative Commons Attribution 4.0 International License (http://creativecommons.org/licenses/by/4.0/), which permits unrestricted use, distribution, and reproduction in any medium, provided you give appropriate credit to the original author(s) and the source, provide a link to the Creative Commons license, and indicate if changes were made.

\section{References}

Akutsu K, Khen CV, Toda MJ (2007) Assessment of higher insect taxa as bioindicators for different logging-disturbance regimes in lowland tropical rain forest in Sabah, Malaysia. Ecol Res 22:542-550. https://doi.org/10.1007/s11284-006-0052-6

Appanah S, Rasol MAM (1990) Smaller trees can fruit in logged dipterocarp forests. J Trop For Sci 3:80-87

Asquith NM, Wright SJ, Clauss MJ (1997) Does mammal community composition control recruitment in neotropical forest? Evidence from Panama. Ecology 78:941-946. https://doi.org/10.1890/00129658(1997)078\%255B0941:DMCCCR\%255D2.0.CO\%253B2

Banks-Leite C, Pardini R, Boscolo D et al (2014) Assessing the utility of statistical adjustments for imperfect detection in tropical conservation science. J Appl Ecol 51:849-859. https://doi. org/10.1111/1365-2664.12272

Bates D, Maechler M, Bolker B, Walker S (2015) Fitting linear mixed-effects models using lme4. J Stat Softw 67:1-48. https://doi.org/10.18637/jss.v067.i01

Bernard H, Bili R, Matsuda I et al (2016) Species richness and distribution of primates in disturbed and converted forest landscapes in Northern Borneo. Trop Conserv Sci 9:1-11. https://doi.org/10.1177/19400 82916680104

Berry NJ, Phillips OL, Lewis SL et al (2010) The high value of logged tropical forests: lessons from northern Borneo. Biodivers Conserv 19:985-997. https://doi.org/10.1007/s10531-010-9779-Z

Bischoff W, Newbery DM, Lingenfelder M et al (2005) Secondary succession and dipterocarp recruitment in Bornean rain forest after logging. For Ecol Manag 218:174-192. https://doi.org/10.1016/j.forec o.2005.07.009

Borchers DL, Efford MG (2008) Spatially explicit maximum likelihood methods for capture-recapture studies. Biometrics 64:377-385. https://doi.org/10.1111/j.1541-0420.2007.00927.x

Brearley FQ, Prajadinata S, Kidd PS et al (2004) Structure and floristics of an old secondary rain forest in Central Kalimantan, Indonesia, and a comparison with adjacent primary forest. For Ecol Manag 195:385-397. https://doi.org/10.1016/j.foreco.2004.02.048

Burivalova Z, Şekercioğlu ÇH, Koh LP (2014) Thresholds of logging intensity to maintain tropical forest biodiversity. Curr Biol 24:1893-1898. https://doi.org/10.1016/j.cub.2014.06.065

Costantini D, Edwards DP, Simons MJP (2016) Life after logging in tropical forests of Borneo: a metaanalysis. Biol Conserv 196:182-188. https://doi.org/10.1016/j.biocon.2016.02.020

Curran LM, Leighton M (2000) Vertebrate responses to spatiotemporal variation in seed production of mast fruiting Dipterocarpaceae. Ecol Monogr 70:101-128

Curran LM, Webb CO (2000) Experimental tests of the spatiotemporal scale of seed predation in mastfruiting Dipterocarpaceae. Ecol Monogr 70:129-148

Curran LM, Caniago I, Paoli GD et al (1999) Impact of El Niño and logging on canopy tree recruitment in Borneo. Science 286:2184-2188. https://doi.org/10.1126/science.286.5447.2184 
Cusack JJ, Wearn OR, Bernard H, Ewers RM (2015) Influence of microhabitat structure and disturbance on detection of native and non-native murids in logged and unlogged forests of northern Borneo. J Trop Ecol 31:25-35. https://doi.org/10.1017/S0266467414000558

Edwards DP, Magrach A, Woodcock P et al (2014a) Selective-logging and oil palm: multitaxon impacts, biodiversity indicators, and trade-offs for conservation planning. Ecol Appl 24:2029-2049. https://doi. org/10.1038/nature 11318

Edwards FA, Edwards DP, Larsen TH et al (2014b) Does logging and forest conversion to oil palm agriculture alter functional diversity in a biodiversity hotspot? Anim Conserv 17:163-173. https://doi. org/10.1111/acv.12074

Efford MG (2013) R Package "SECR": Functions to estimate the density and size of a spatially distributed animal population sampled with an array of passive detectors, such as traps, or by searching polygons or transects

Emmons LH (2000) Tupai: a field study of Bornean treeshrews. University of California Press, Berkley

Ewers RM, Didham RK, Fahrig L et al (2011) A large-scale forest fragmentation experiment: the Stability of Altered Forest Ecosystems Project. Philos Trans R Soc B Biol Sci 366:3292-3302. https:// doi.org/10.1098/rstb.2011.0049

Ferraz G, Russell GJ, Stouffer PC et al (2003) Rates of species loss from Amazonian forest fragments. Proc Natl Acad Sci USA 100:14069-14073

Fitzherbert EB, Struebig MJ, Morel A et al (2008) How will oil palm expansion affect biodiversity? Trends Ecol Evol 23:538-545. https://doi.org/10.1016/j.tree.2008.06.012

Ghazoul J (2016) Dipterocarp ecology, biology and conservation, 1st edn. Oxford University Press, Oxford

Gibson L, Lee TM, Koh LP et al (2011) Primary forests are irreplaceable for sustaining tropical biodiversity. Nature. https://doi.org/10.1038/nature10425

Gibson L, Lynam AJ, Bradshaw CJA et al (2013) Near-complete extinction of native small mammal fauna 25 years after forest fragmentation. Science 341:1508-1510. https://doi.org/10.1126/science.1240495

Guariguata MR, Claire HA-L, Jones G (2002) Tree seed fate in a logged and fragmented forest landscape, Northeastern Costa Rica. Biotropica 34:405-415. https://doi.org/10.1111/j.1744-7429.2002.tb00554.x

Guillera-Arroita G, Lahoz-Monfort JJ, MacKenzie DI et al (2014) Ignoring imperfect detection in biological surveys is dangerous: a response to "fitting and interpreting occupancy models". PLoS ONE 9:e99571. https://doi.org/10.1371/journal.pone.0099571

Isabirye-Basuta G, Kasenene JM (1987) Small rodent populations in selectively felled and mature tracts of Kibale Forest, Uganda. Biotropica 19:260-266

Johns AD (1988) Effects of "Selective" timber extraction on rain forest structure and composition and some consequences for frugivores and folivores. Biotropica 20:31-37

Johns AG (1997) Timber production and biodiversity conservation in tropical rain forests. Cambridge University Press, Cambridge

Kellner KF, Swihart RK (2014) Accounting for imperfect detection in ecology: a quantitative review. PLoS ONE 9:e111436. https://doi.org/10.1371/journal.pone.0111436

Kuussaari M, Bommarco R, Heikkinen RK et al (2009) Extinction debt: a challenge for biodiversity conservation. Trends Ecol Evol 24:564-571. https://doi.org/10.1016/j.tree.2009.04.011

Liebsch D, Marques MCM, Goldenberg R (2008) How long does the Atlantic Rain Forest take to recover after a disturbance? Changes in species composition and ecological features during secondary succession. Biol Conserv 141:1717-1725. https://doi.org/10.1016/j.biocon.2008.04.013

Lindenmayer DB, Likens GE, Andersen A et al (2012) Value of long-term ecological studies. Aust Ecol 37:745-757. https://doi.org/10.1111/j.1442-9993.2011.02351.x

Meijaard E, Sheil D (2008) The persistence and conservation of Borneo's mammals in lowland rain forests managed for timber: observations, overviews and opportunities. Ecol Res 23:21-34. https://doi. org/10.1007/s 11284-007-0342-7

Nakagawa M, Itioka T, Momose K et al (2003) Resource use of insect seed predators during general flowering and seeding events in a Bornean dipterocarp rain forest. Bull Entomol Res 93:455-466. https://doi.org/10.1079/BER2003257

Nakagawa M, Hyodo F, Nakashizuka T (2007a) Effect of forest use on trophic levels of small mammals: an analysis using stable isotopes. Can J Zool 85:472-478. https://doi.org/10.1139/Z07-026

Nakagawa M, Miguchi H, Sato K et al (2007b) Population dynamics of arboreal and terrestrial small mammals in a tropical rainforest, Sarawak, Malaysia. Raffles Bull Zool 55:389-395

Nakagawa M, Miguchi H, Sato K, Nakashizuka T (2007c) A preliminary study of two sympatric Maxomys rats in Sarawak, Malaysia: spacing patterns and population dynamics. Raffles Bull Zool 55:381-387

Pardini R (2004) Effects of forest fragmentation on small mammals in an Atlantic Forest landscape. Biodivers Conserv 13:2567-2586. https://doi.org/10.1023/B:BIOC.0000048452.18878.2d 
Payne J, Francis CM (1985) A field guide to the mammals of Borneo. The Sabah Society, Kota Kinabalu

Pfeifer M, Lefebvre V, Turner E et al (2015) Deadwood biomass: an underestimated carbon stock in degraded tropical forests? Environ Res Lett 10:044019. https://doi.org/10.1088/17489326/10/4/044019

Pfeifer M, Kor L, Nilus R et al (2016) Mapping the structure of Borneo's tropical forests across a degradation gradient. Remote Sens Environ 176:84-97. https://doi.org/10.1016/j.rse.2016.01.014

Püttker T, Pardini R, Meyer-Lucht Y, Sommer S (2008) Responses of five small mammal species to micro-scale variations in vegetation structure in secondary Atlantic Forest remnants, Brazil. BMC Ecol. https://doi.org/10.1186/1472-6785-8-9

Putz FE, Zuidema PA, Synnott T et al (2012) Sustaining conservation values in selectively logged tropical forests: the attained and the attainable. Conserv Lett 5:296-303. https://doi.org/10.1111/j.1755263X.2012.00242.x

R Core Team (2018) R: A language and environment for statistical computing. R Foundation for Statistical Computing, Vienna, Austria. https://www.R-project.org/

Royle JA, Chandler RB, Sollmann R, Gardner B (2013) Spatial capture-recapture. Academic Press, Cambridge

Sikes RS, Gannon WL, Mammalologists AC and UC of the AS (2011) Guidelines of the American Society of Mammalogists for the use of wild mammals in research. J Mammal 92:235-253. https://doi. org/10.1644/10-mamm-f-355.1

Sodhi NS, Posa MRC, Lee TM et al (2010) The state and conservation of Southeast Asian biodiversity. Biodivers Conserv 19:317-328. https://doi.org/10.1007/s10531-009-9607-5

Vieira MV, Olifiers N, Delciellos AC et al (2009) Land use vs. fragment size and isolation as determinants of small mammal composition and richness in Atlantic Forest remnants. Biol Conserv 142:1191-1200. https://doi.org/10.1016/j.biocon.2009.02.006

Villéger S, Mason WH, Mouillot D (2008) New multidimensional functional diversity indices for a multifaceted framework. Ecology 89:2290-2301

Warren-Thomas E, Dolman PM, Edwards DP (2015) Increasing demand for natural rubber necessitates a robust sustainability initiative to mitigate impacts on tropical biodiversity. Conserv Lett 8:230-241. https://doi.org/10.1111/conl.12170

Wearn OR, Reuman DC, Ewers RM (2012) Extinction debt and windows of conservation opportunity in the Brazilian Amazon. Science 337:228-231

Wearn OR, Carbone C, Rowcliffe JM et al (2016) Grain-dependent responses of mammalian diversity to land use and the implications for conservation set-aside. Ecol Appl 26:1409-1420. https://doi. org/10.1890/15-1363

Wearn OR, Rowcliffe JM, Carbone C et al (2017) Mammalian species abundance across a gradient of tropical land-use intensity: a hierarchical multi-species modelling approach. Biol Conserv 212:162-171. https://doi.org/10.1016/j.biocon.2017.05.007

Wells K, Bagchi R (2005) Eat in or take away: seed predation and removal by rats (Muridae) during a fruiting event in a dipterocarp rainforest. Raffles Bull Zool 53:281-286

Wells K, Kalko EKV, Lakim MB (2007) Effects of rain forest logging on species richness and assemblage composition of small mammals in Southeast Asia. J Biogeogr. https://doi.org/10.111 1/j.1365-2699.2006.01677.x

\section{Affiliations}

\section{Philip M. Chapman ${ }^{1,2}$ D . Oliver R. Wearn² $\cdot$ Terhi Riutta $^{1,3} \cdot$ Chris Carbone $^{2}$. J. Marcus Rowcliffe ${ }^{2} \cdot$ Henry Bernard $^{4} \cdot$ Robert. M. Ewers $^{1}$}

1 Department of Life Sciences, Imperial College London, Silwood Park, Buckhurst Road, Ascot, Berkshire SL5 7PY, UK

2 Institute of Zoology, Zoological Society of London, Outer Circle, Regent's Park, London NW1 4RY, UK

3 School of Geography and the Environment, University of Oxford, S Parks Rd, Oxford OX1 3QY, UK

4 Institute for Tropical Biology and Conservation, Universiti Malaysia Sabah, 88400 Kota Kinabalu, Malaysia 